\title{
Optic nerve involvement in a case of methanol poisoning
}

\author{
PETER NAESER \\ From the Department of Ophthalmology, Uppsala University, Uppsala, Sweden
}

SUMMARY The eyes and optic nerves were studied histologically in a fatal case of methanol poisoning in a 37-year-old man. The most striking findings were bilateral central necrosis of the optic nerves from behind the lamina cribrosa to the orbital apex. Proximal parts of the nerve and the tract showed no necrosis. It is suggested that the complex blood supply of the nerve may be of importance.

Methanol intoxication is a well known cause of blindness in man, the most common observation being oedema of the posterior retina and the optic nerve head. Later optic nerve atrophy develops. The whole sequence of events is thoroughly described by Benton and Calhoun ${ }^{1}$ from the Atlanta catasrophe, when 320 persons sought emergency medical care after drinking whisky containing $35 \%$ methanol and $15 \%$ ethanol. Post-mortem examinations of affected eyes have mainly been concentrated on the retina, where oedema and ganglion cell degeneration have been the main findings. ${ }^{23}$ However, although optic nerve lesions has been suspected, the optic nerve has only infrequently been investigated.

The object of the present report is to describe a lethal case of methanol poisoning in which optic nerve changes were found.

\section{Case history}

The patient, a 42-year-old man, was admitted to the University Hospital in Uppsala after drinking on the previous day a liquor which was later found to contain $80 \%$ methanol and no ethanol. On admission he was unconscious and severely acidotic. He had a blood methanol concentration of $114 \mathrm{mmol} / \mathrm{l}$. No ethanol could be detected. The acidosis was corrected within a short time and the methanol concentration diminished by peritoneal dialysis. He was seen by an ophthalmologist on the third day. The pupils were small but reacted to light with a small amplitude. Bilaterally there was slight oedema of the optic nerve heads and of the retinae at the posterior

Correspondence to Dr P Naeser, Department of Ophthalmology, University Hospital, S-750 14 Uppsala 14, Sweden. pole. There were no haemorrhages. Computed tomography of the cranium on the same day revealed bilateral necrosis of the putamen regions. ${ }^{4}$ The patient developed pneumonia which was resistant to treatment, and, still unconscious, he died on the 20th day after the accident.

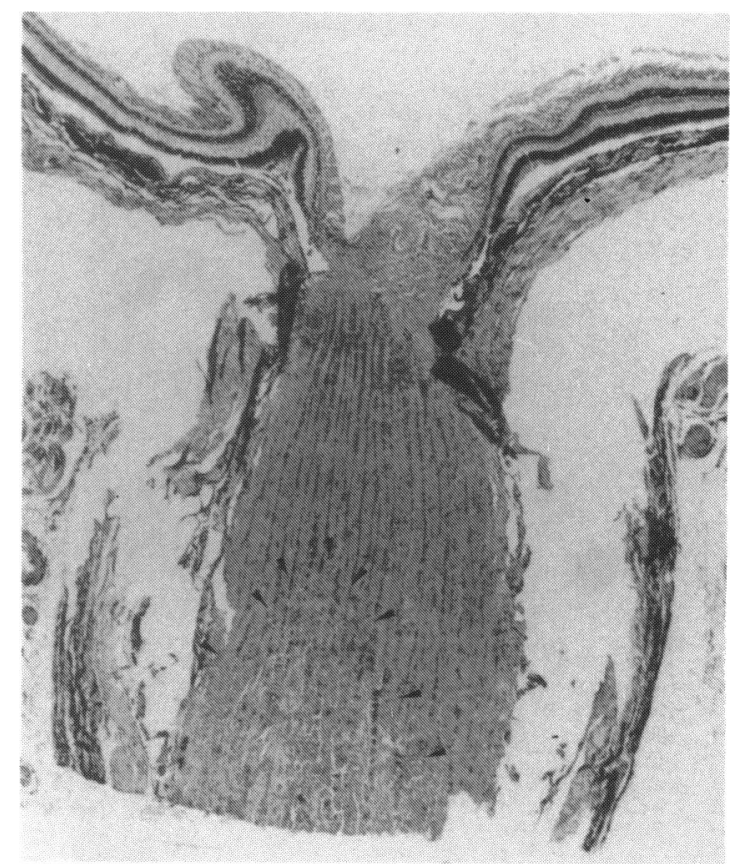

Fig. 1 Optic nerve head showing the central necrosis ending before the nerve fibres reach the lamina cribrosa (arrows). Luxol fast blue, $\times 8$. 


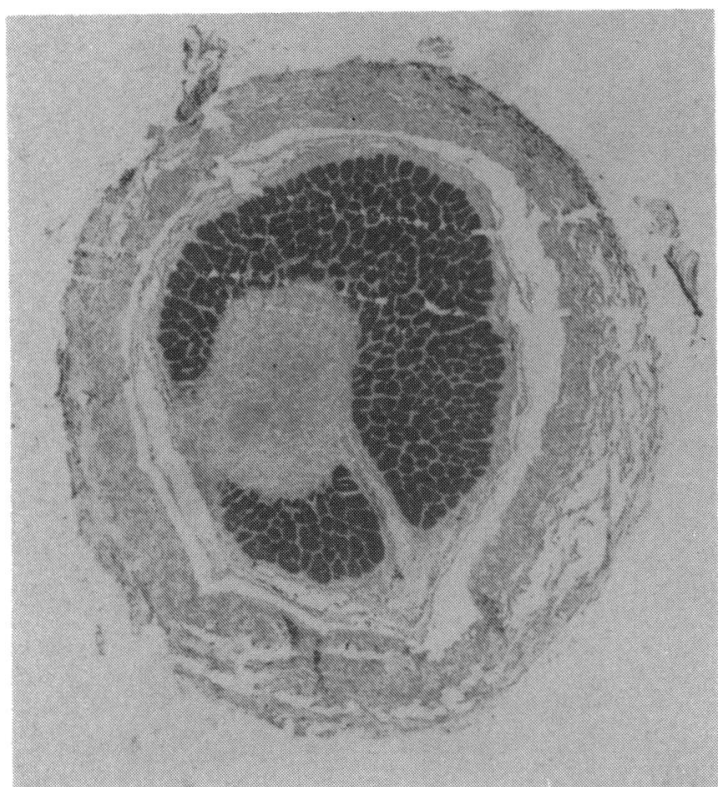

Fig. 2A

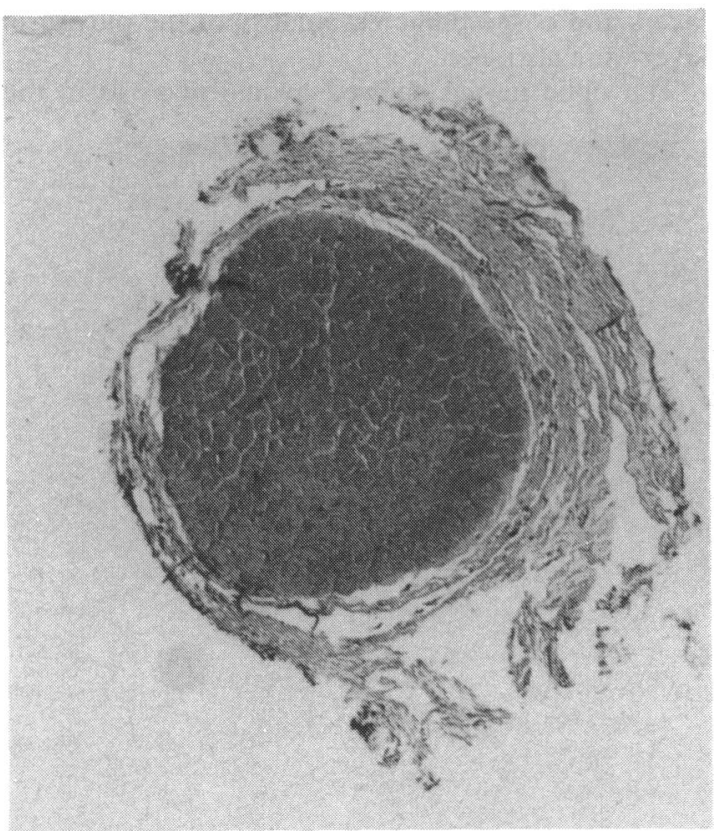

Fig. 2C

OCULAR PATHOLOGY

Both eyes with their optic nerves and tracts were investigated after formalin fixation. The eyes were opened horizontally and showed pale, slightly wrinkled retinae without visable haemorrhage. The histological sections from the eye globes displayed no changes in the anterior segment. The optic nerve

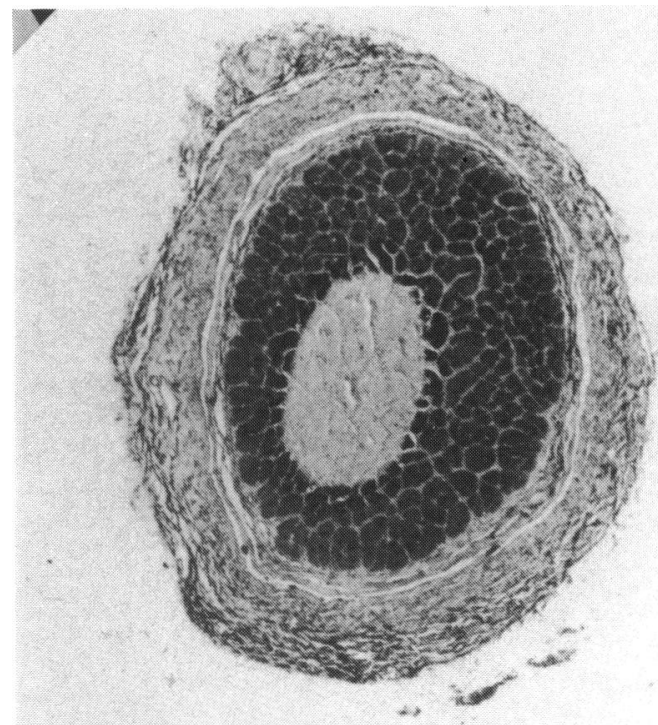

Fig. 2B

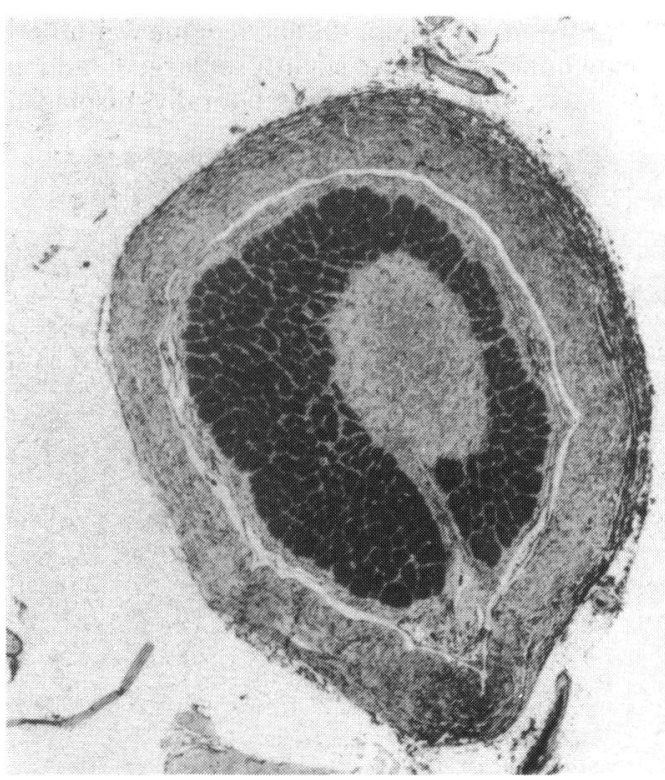

Fig. 2D

Fig. 2 Cross sections of the right $(\mathrm{A}-\mathrm{C})$ and left $(\mathrm{D}-\mathrm{F})$ optic nerve taken $1 \mathrm{~cm}(\mathrm{~A}$ and $\mathrm{D})$ and $2 \mathrm{~cm}(\mathrm{~B}$ and $\mathrm{E})$ behind the eye globe and from the apical region $(\mathrm{C}$ and $\mathrm{F})$. The central necrosis is seen in the anterior parts of the nerve (A-C). A-C: $H$ and $E, \times 7 \cdot 5, \mathrm{D}-\mathrm{F}$ : luxol fast blue, $\times 9$.

heads looked normal, but the cut surface of the orbital parts of the optic nerves showed pale central areas. This change was not seen in the optic canal parts of the nerves or in the optic tracts. 


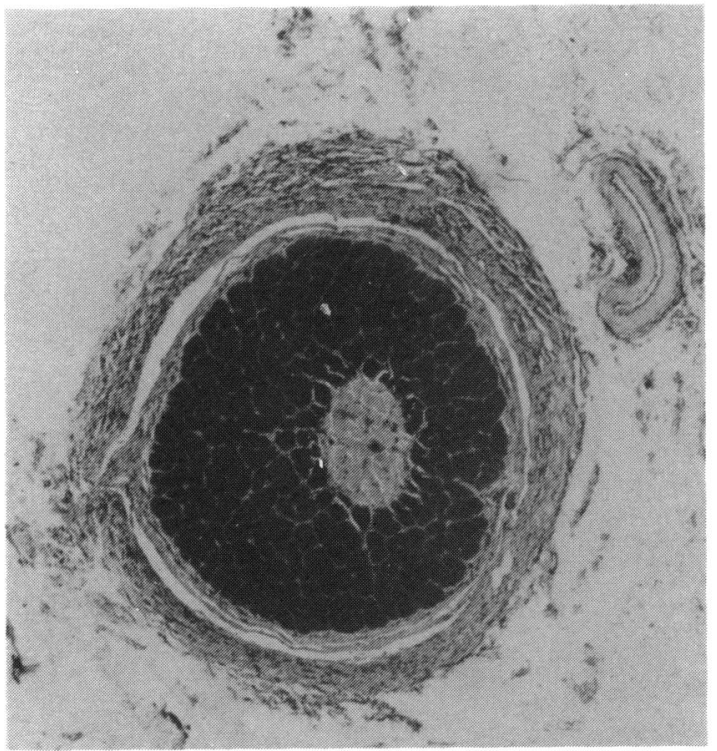

Fig. 2E

Each retina was partly detached by a subretinal serous effusion, and slight retinal oedema was noted. The ganglion cells were slightly enlarged, and in many places the nuclei were laterally displaced.

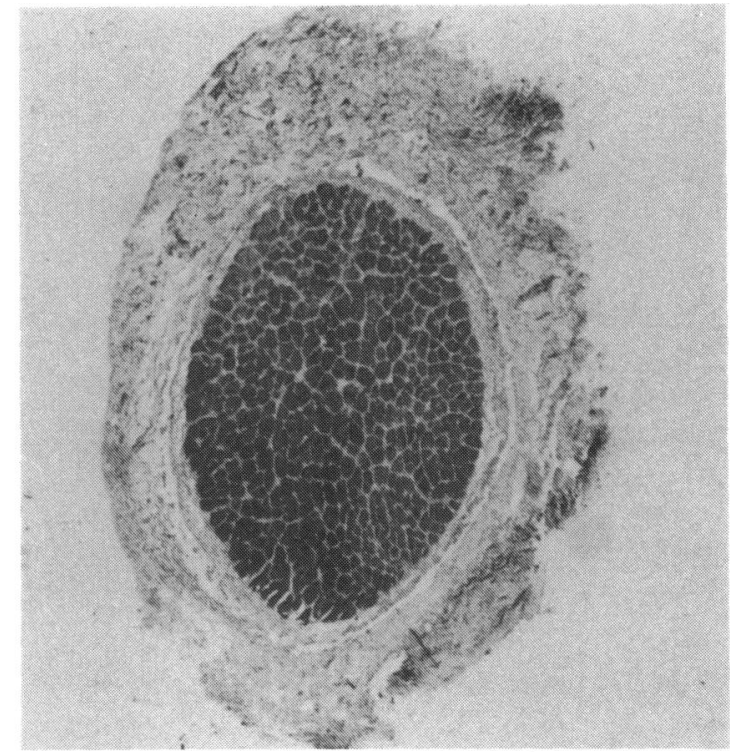

Fig. 2F

Slight irregularity of the outer and inner nuclear layers and eosinophilic granularity of the plexiform layer were also seen.

The optic nerves showed axonal necrosis in the

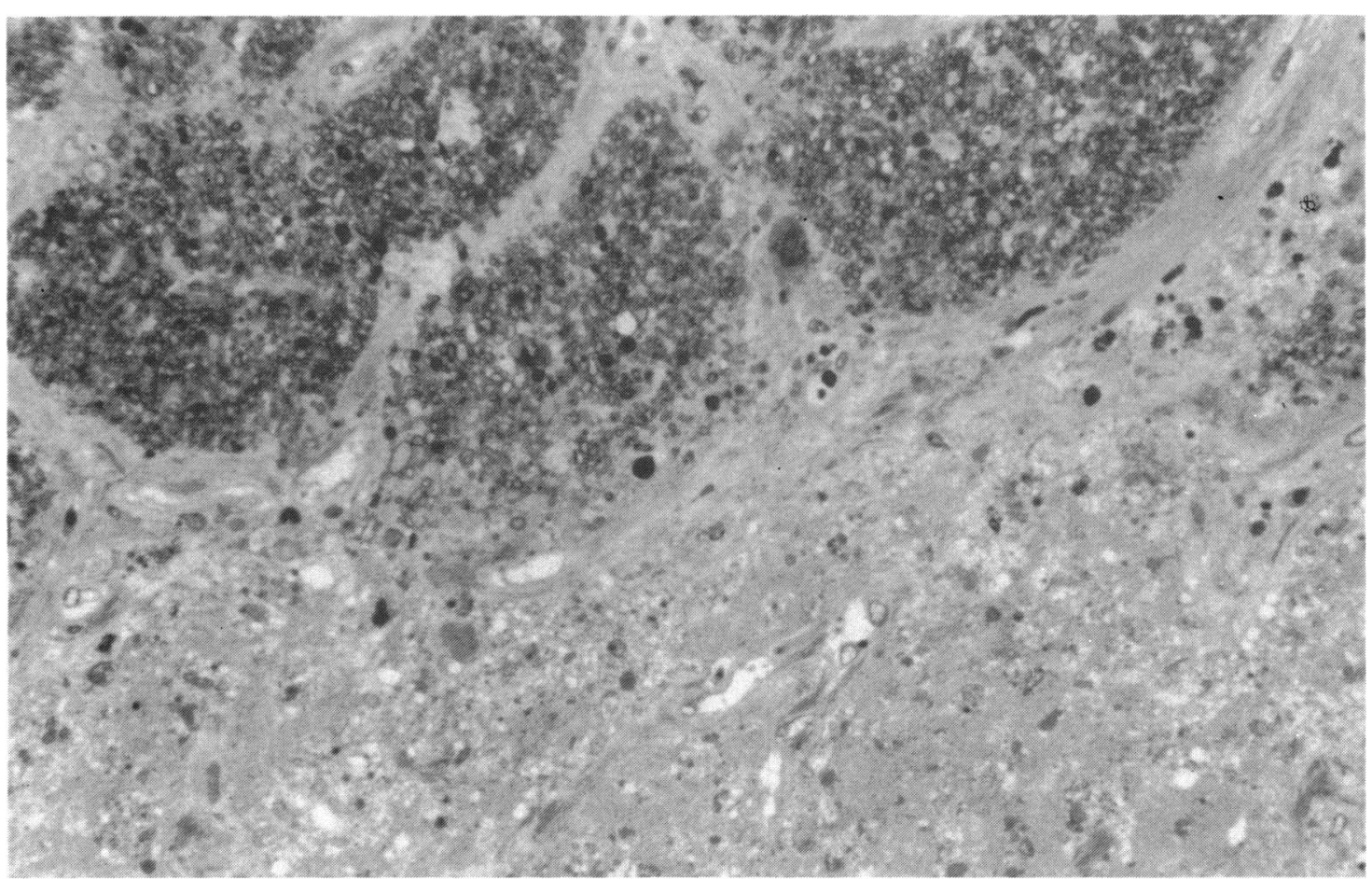

Fig. 3 High-power micrograph from the border between the necrotic (lower part) and the normally appearing nerve fibres. Note the lack of inflammatory reaction. Toluidine biue, $\times 430$. 
centre, with a sharp border where they met the normally appearing axons in the periphery. The changes extended from $1 \mathrm{~mm}$ behind the lamina cribrosa (Fig. 1) to the orbital apex (Figs. 2A-F). There was no inflammatory reaction adjacent to the necrosis (Fig. 3). The lumina of the vessels were open. Myelin staining of the nerve from within the optic canal or from the optic tracts displayed paler staining than normal, possibly due to post-mortem changes. There were, however, no necrotic changes in the nerve proximal to the orbit. The lateral genicular nucleus appeared normal.

\section{Discussion}

The changes in the optic nerves are remarkable. Many authors have speculated about a possible optic nerve lesion but only oedema of the nerve has been reported..$^{356}$ The changes in the retinal ganglion cells have been postulated to be secondary to retrograde degeneration of optic nerve axons and not caused by the methanol intoxication itself. ${ }^{37-9}$ In recent reports myelin change in the retrolaminal pert of the nerve was observed. ${ }^{10-12}$ Animal experiments have also shown optic nerve involvement. Birch-Hirschfeld ${ }^{13}$ described myelin degeneration in a rabbit two weeks after methanol poisoning. Signs of axonal necrosis combined with venous congestion and oedema were seen in apes by Pick and Bielschowsky ${ }^{5}$ after 2-3 weeks. In an experiment with rabbits Fanta and Mayer-Oberditsch ${ }^{14}$ found only optic nerve oedema.

The selective bilateral damage of the orbital part of the optic nerve is difficult to understand. In the cases reported the changes started $1-2 \mathrm{~mm}$ behind the lamina cribrosa and involved the orbital part of the nerve only. The blood supply may be of importance. The immediate postlaminar part is abundantly supplied by the short posterior ciliary artery. The orbital part is supplied by the pial plexus, with branches from the ophthalmic artery extending perpendicularly into the nerve, providing a generous perfusion especially of the nerves at the periphery. ${ }^{15}$ This may to some extent explain why the central part of the nerve is more vulnerable. The perfusion of the central parts of the nerve from a central optic nerve vessel with different extension may be of importance. ${ }^{1617}$ The central infarctions suggest a collapse of the capillary bed, as has been suggested for similar changes in a case of bilateral ischaemic optic neuropathy. ${ }^{18}$

The skilful technical assistance of Margareta Björling is gratefully acknowledged.

\section{References}

1 Benton CD, Calhoun FP. The ocular effects of methyl alcohol poisoning. Report of a catastrophe involving 320 persons. Ophthalmology 1980; 56: 875-85.

2 Fink WH. The ocular pathology of methyl alcohol poisoning. Am J Ophthalmol 1943; 26: 694-709.

3 Fink WH. The ocular pathology of methyl alcohol poisoning. Part II. Am J Ophthalmol 1943; 26: 802-15.

4 Aquilonius SM, Bergström K, Enoksson P, et al. Cerebral computed tomography in methanol intoxication. J Comput Assist Tomogr 1980; 4: 425-8.

5 Pick L, Bielschowsky M. Über histologische Befunde im Auge und im centralen Nervensystem des Menschen bei akuter tötlicher Vergiftung mit Methylalkohol. Berl Klin Wochenschr 1912; 49: 888-93.

6 Menne FR. Acute methyl alcohol poisoning. A report of twentytwo instances with post mortem examinations. Arch Pathol 1939; 26: 77-92.

7 MacDonald AE. The pathology of methyl alcohol amblyopia. XIII International Ophthalmology Congress, Amsterdam, Holland. 1929: 440-5.

8 Röe D. The ganglion cells of the retina in cases of methanol poisoning in human beeings and experimental animals. Acta Ophthalmol (Kbh) 1948; 26: 169-82.

9 Potts AM, Praglin J, Farkas J, Orbison L, Chickering D. Studies on the visual toxicity of methanol: VIII. Additional observations on methanol poisoning in the primate test object. Am J Ophthalmol 1955; 40: 76-83.

10 Lindenberg R, Walch FB, Sacks JG. Neuropathology of vision: an atlas. Philadelphia: Lea and Febiger, 1973; 10, 118.

11 Collyer RT. Methyl alcohol toxicity. A case report. In: Yanoff M, Fine BS, eds. Ocular pathology. A text and atlas. 2nd ed. Philadelphia: Harper and Row, 1982: 627.

12 Sharp JA, Hostovsky M, Bilbao JM, Rewcastle NB. Methanol optic neuropathy: a histopathological study. Neurology 1982; 32: 1093-100.

13 Birch-Hirschfeld A. Experimentelle Untersuchungen über die Pathogenese der Methylalkoholamblyopie Graefes Arch Clin Exp Ophthalmol 1901; 52: 358-83.

14 Fanta H, Mayer-Oberditsch I. Ein Beiträg zur Pathologie im Sehnerven bei Methylalkoholvergiftung (Tierversuche). Klin Monatsbl Augenheilkd 1953; 122: 288-394.

15 Lieberman MF, Maumenee AE, Green WR. Histologic studies of the vasculature of the anterior optic nerve. Am J Ophthalmol 1976; 82: 405-23.

16 François J, Neetens A. Central retinal artery and central optic nerve artery. Br J Ophthalmol 1963; 47: 21-30.

17 Goder G. The capillaries of the optic nerve. Am J Ophthalmol 1974: 77: 684-9.

18 Rootman J, Butler D. Ischaemic optic neuropathy - a combined mechanism. Br J Ophthalmol 1980; 64: 826-31. 